\title{
Molar Cusps in Southern Chinese
}

\author{
John Y.K. Ling and Ricky W.K. Wong*
}

Orthodontics, University of Hong Kong, Hong Kong

\begin{abstract}
Aim: To investigate the number of molar cusps of the Southern Chinese and compare these with studies in different populations.

Materials and Methods: The number of molar cusps of study casts of an unselected sample from a 12 year old Hong Kong Oral Health Survey of 12 year old children ( $\mathrm{n}=459 ; 295$ boys and 164 girls) were studied.

Results: For upper first molars, 5-cusp molars were the most prevalent in males (39\%) while 4-cusp molars were the most prevalent in females (39\%). For lower first molars, 5-cusp molars were the most prevalent in both sexes $(63 \%-72 \%)$. For lower second molars, 5 -cusp molars were the most prevalent in both sexes (43\%-53\%).

Conclusion: Different from traditionally described, the Southern Chinese has more 5-cusp lower second molars than the 4cusp ones.
\end{abstract}

Keywords: Molar cusp, Southern Chinese.

\section{INTRODUCTION}

It is generally believed that the numerous morphologic characteristics of the teeth are genetically determined $[1,2]$. Detailed description and study of these traits could provide valuable information regarding phylogeny of man and distinctions between races and subraces [1,3-12]. Features of morphology which closely reflect genetic structure should be examined in determining the evolutionary (phylogenetic) relationships of populations and in establishing taxonomies that reflect these relationships [12]. Although tooth morphology may be an indicator of genetic distances between populations, it should be viewed with caution [11]. The study of the number of cusps are not only important in anthropology, it is also important in the study of dental occlusion, orthodontics, restorative dentistry and prosthetic dentistry.

In modern man, the number of cusps of the upper molars is frequently reduced from four to three. The formula for the number of cusps of the upper molar series is changing from $4-4-4$ to $4-4-3$ and $4-3-3$. The trend is more marked in females than in males of all populations that have been studied. In most studies, males generally showed a lesser tendency than females to reduction in the number of cusps of the upper molars. The process of reduction occurs through the elimination of the hypocone or distolingual cusp, with a subsequent decrease in the mesiodistal crown diameter and in the occlusal area.

Moorrees [1] reported that living Aleut females possessed fewer five-cusped second molars than males, the difference being significant (N.B. small sample size of 36). In

*Address correspondence to this author at the $2 / \mathrm{F}$, Orthodontics, Prince Philip Dental Hospital, 34 Hospital Road, Sai Ying Pun, Hong Kong; Tel: 852 28590554; Fax: 852 25593803; E-mail: fyoung@hkucc.hku.hk the Aleuts, the frequency of 4 cusps is $100 \%$ for the first molars, $69 \%$ for the 2 nd molars and $31 \%$ for the 3 rd molars.

There are normally five main cusps on a lower molar. The fifth or disto-buccal cusp is the most variable, which may be absent. If the fifth cusp is present it is often placed lingually, out of line with the other two buccal cusps. The fifth cusp may be divided into two parts by a fissure which runs antero-posteriorly, thus the tooth may have three lingual and three buccal cusps [8]. A total of ten cusps can be theoretically present on a lower molar tooth. There is a large amount of publications on molar morphology, numbers of molar cusps, origins, and evolution of both cusps and teeth [13]. There are no standards yet available to determine whether a cusp should be recorded as one because of its inadequate size.

Suzuki \& Sakai [14] found no significant differences in first and second molar cusp numbers of 392 male and female Japanese.

The frequency of cusp 6 on first and second molars [65 and $63 \%$ respectively] from Indian crania was found to be about three times that of Aleuts (21 and $18 \%$ ) and Eskimos (22 and $18 \%$ ). All three groups (Indian, Aleuts and Eskimos) showed five or six cusped first lower molars. No fourcusped molars were found. Four-cusped second lower molars occurred most often in the Aleuts [9\%], less in Indians [3 $\%$ ] and least in the Eskimos [1\%] [15].

Europeans and American Whites have the highest and unique frequency of four-cusped lower first molars $(10 \%)$ while the rest of the world's populations that have been sampled, which included African and American Negroes, Australians, Melanesians, Chinese, Japanese, Aini and native Americans, possessed on the average less than $3 \%$ four cusped first lower molars [16-18]. 
Moorrees [1] stated that bilateral symmetry was perfect for lower molars, permitting him to report his observations on an individual basis. Cusp 6 was infrequently present on the lower second molar when it was not expressed on the first molar in Southwest Indians [19]. This accounted for the moderate association for cusp 6 between these teeth. This pattern was in line with the concept of field effect. Dahlberg [20] concluded that the field for cusp 6 had reversed polarity, that is the field is reversed for size but not for total incidence.

Dental traits generally showed a positive correlation with tooth size, which probably explains why the inter-trait correlations are mostly positive [21]. Dahlberg [22] presented evidence for a relationship between cusp number and tooth size.

Sexual dimorphism in cusp number was evident in that females tend to have more cusps for the same crown diameter. Larger teeth of the same class had a greater number of cusps [23].

'Southern Chinese' are defined as those Chinese whose ancestors originated from provinces south of the Yangtze River and they speak different dialects from the northerners. There is no study about the prevalent of various dental morphologies in this population.

The aim of our study is to investigate the cusp numbers of the upper first permanent molars and lower first and second permanent molars of the Southern Chinese and compare these with studies in different populations.

\section{MATERIALS AND METHODS}

Dental study casts ( $\mathrm{n}=459 ; 295$ boys and 164 girls) were obtained as part of a multi-disciplinary survey of crosssectional, randomly selected sample of 1247 12-year-old Chinese children from the Oral Health Project in Hong Kong $[24,25]$. The participants needed to complete a questionnaire to ask about the country and province in origin of both father and mother. Teeth found to be carious, missing, restored at the measurement landmark, hypoplastic, worn or malformed or orthodontically moved were excluded from the present investigation. Damaged casts which made the assessment data questionable were also omitted. Only study casts with permanent dentition were included in the study. The number of cusps of the upper first permanent molars and lower first and second permanent molars were recorded. Any elevation of enamel that was tuberculate in form occurring at an expected cusp location with a free apex was considered to be a cusp regardless of its size.

\section{RESULTS}

Table 1 shows the frequency distribution of number of cusps of the permanent molars in both arches. For upper first molars, 5-cusp molars were the most prevalent in males (39\%) while 4-cusp molars were the most prevalent in females $(39 \%)$. For lower first molars, 5-cusp molars were the most prevalent in both sexes (63\%-72\%). For lower second molars, 5-cusp molars were the most prevalent in both sexes (43\%-53\%). Very few 4 cusped lower first permanent molars were noted $(1 \%)$, unlike the lower second permanent molars which have $34 \%$ and $41 \%$ four cusps for males and females respectively.

\section{DISCUSSION}

This young age group of Southern Chinese was chosen for measurement to minimize the alteration of the dental arch dimensions because of attrition, restoration or caries. Efforts were made to ensure randomization and adequate sample size to ensure validity.

With the above results, the number of molar cusps in Southern Chinese is compared with other population as below:

For upper first molars:

From Table 1, while most upper first molars were described as having 4 cusps (29\%-39\%), there existed 1\% male in this sample that had only 3 cusps.

Equally as abundance as 4 cusps were the 5-cusps upper first molars (30\%-39\%). As described by Scott and Turner [26], cusp 5 in upper first molars was termed distal accessory tubercle, metaconule and this trait took the form of an occlusal tubercle on the distal marginal ridge of the upper molars. It was positioned between the metacone and the hypocone although it was more closely associated with the metacone. For an accessory tubercle, this trait showed a relatively wide range.

From Scott and Turner [27] the geographic variation in cusp 5 of the upper first molar could be summarized in the following manner:

(1) Low frequency groups (10-25\%): Western Eurasia, Sino-Americas.
Intermediate (30-40\%): Sunda-Pacific, Sub-Saharan Africa?

High frequency groups (45-60\%): Sahul-Pacific, SubSaharan Africa?

Therefore, the data from the Southern Chinese fitted the intermediate frequency groups.

In addition, there existed 6-cusps upper first molar, which were quite common (21\%-24\%), around two-thirds of 5 -cusps upper first molars; and some 7-cusps upper first molars (5\%-7\%); and 8-cusps upper first molars (2\%-4\%).

For lower first molars:

From Table 1, while most lower first molars were described as having 5 cusps $(63 \%-72 \%)$, there existed some cases $(0.5 \%, 36$, male) in this sample that had only 3 cusps and some cases (1\%) in this sample that had only 4 cusps.

From Scott and Turner [28] geographic variation in lower molar cusp number shows the following pattern:

Lower first molar (4-cusped forms)

(1) Low frequency groups (0-3\%); Sub-Saharan Africa, Sino-Americas, Sunda-Pacific, Australia.

(2) Intermediate (5-10\%): New Guinea, Melanesia, prehistoric Europe.

(3) High frequency groups (10-20\%): Western Eurasia.

Therefore, the data from the Southern Chinese fitted the low frequency groups. 
Table 1. Prevalence (\%) of Number of Cusps of Upper First Molars and the Lower First and Second Molars in 12 Year Old Southern Chinese Males $(n=270)$ and Females $(n=149)$

Upper Arch

\begin{tabular}{|c|c|c|c|c|}
\hline \multirow[b]{3}{*}{ Number of Cusps } & \multicolumn{2}{|c|}{ Males } & \multicolumn{2}{|c|}{ Females } \\
\hline & \multicolumn{2}{|c|}{$(n=270)$} & \multicolumn{2}{|c|}{$(n=149)$} \\
\hline & 16 & 26 & 16 & 26 \\
\hline 3 cusps & 1 & 1 & 0 & 0 \\
\hline 4 cusps & 30 & 29 & 39 & 39 \\
\hline 5 cusps & 39 & 39 & 30 & 30 \\
\hline 6 cusps & 22 & 24 & 21 & 21 \\
\hline 7 cusps & 6 & 5 & 7 & 6 \\
\hline 8 or more cusps & 3 & 2 & 3 & 4 \\
\hline
\end{tabular}

Lower Arch

\begin{tabular}{|c|c|c|c|c|c|c|c|c|}
\hline \multirow[b]{3}{*}{ Number of Cusps } & \multirow{2}{*}{\multicolumn{2}{|c|}{$\begin{array}{c}\text { Males } \\
(n=262)\end{array}$}} & \multirow{2}{*}{\multicolumn{2}{|c|}{$\begin{array}{l}\text { Females } \\
(n=145)\end{array}$}} & \multirow{2}{*}{\multicolumn{2}{|c|}{$\begin{array}{c}\text { Males } \\
(n=118)\end{array}$}} & \multirow{2}{*}{\multicolumn{2}{|c|}{$\begin{array}{c}\text { Females } \\
(n=81)\end{array}$}} \\
\hline & & & & & & & & \\
\hline & 36 & 46 & 36 & 46 & 37 & 47 & 37 & 47 \\
\hline 3 cusps & 0.5 & 0 & 0 & 0 & 0 & 0 & 0 & 0 \\
\hline 4 cusps & 1 & 1 & 1 & 1 & 31 & 36 & 39 & 43 \\
\hline 5 cusps & 64 & 63 & 72 & 70 & 53 & 45 & 45 & 43 \\
\hline 6 cusps & 31 & 32 & 22 & 23 & 14 & 18 & 14 & 13 \\
\hline 7 cusps & 3 & 3 & 5 & 5 & 2 & 1 & 2 & 1 \\
\hline 8 or more cusps & 0 & 0 & 0 & 0 & 0 & 0 & 0 & 0 \\
\hline
\end{tabular}

In addition, there existed 6-cusps lower first molar, which were quite common (22\%-32\%), around one half of 5 cusps lower first molars;

From Scott and Turner [29] cusp 6 lower first molar on a world scale was summarized as follows:

(1) Low frequency groups (0-10\%): Western Eurasia.

(2) Low intermediate (10-20\%): Sub-Saharan Africa, South Siberia, Altaic-speakers, New Guinea.

(3) High intermediate (30-50\%): North and East Asia, Americas, Melanesia.

(4) High frequency groups ( $>50 \%)$ : Polynesia, Australia.

Therefore, the data from the Southern Chinese fitted the intermediate frequency groups.

Furthermore, there existed some 7-cusps lower first molars (3\%-5\%). Scott and Turner [30] summarized world values for more than 270 samples, confirmed this succinct characterization of cusp 7 variation. They suggested this was a trait common in Africa and rare, or at least uncommon, in all other human groups and it was difficult to even trichotomize variation as there was no distinct pattern evident among the low frequency groups:
(1) Low frequency groups (0-10\%): Western Eurasia, Sino-Americas, Sunda-Pacific, Sahul-Pacific.

(2) High frequency groups (25-40\%): Sub-Saharan Africa.

Therefore, the data from the Southern Chinese fitted the low frequency groups.

For lower second molars:

From Table 1, while many lower second molars were described as having 4 cusps (31\%-43\%), most lower second molars were identified as having 5 cusps (43\%-53\%), and some cases $(13-18 \%)$ in this sample that had 6 cusps and some even have 7 cusps (1\%-2\%).

Scott and Turner [30] summarized world values for lower second molar (4-cusped forms):

(1) Low frequency groups (10-30\%): San, Americas.

(2) Low intermediate (30-60\%): South Africa, East Asia, North Asia, Altaic (Mongolian/Tungusic), SundaPacific, Australia.

(3) High intermediate (60-80\%): New Guinea, Melanesia; East Africa, Altaic (Turkic).

(4) High frequency groups $(>80 \%)$ : Western Eurasia. 
Therefore, the data from the Southern Chinese fitted the low intermediate frequency groups.

The lower second molars are usually described as having 4 essential cusps [31]. The finding that the Southern Chinese has more 5-cusp lower second molars than the 4-cusp ones is an exception to this rule.

\section{CONCLUSION}

Different from traditionally described, the Southern Chinese has more 5-cusp lower second molars than the 4-cusp ones.

\section{REFERENCES}

[1] Moorrees CFA. The Aleut dentition. Cambridge: Harvard University Press 1957.

[2] Lundstrom A. Tooth morphology as a basis for distinguishing monozygotic and dizygotic twins. Swed Med Res Counc 1962; 34-43.

[3] Hrdlicka A. Shovel-shaped teeth. Am J Phys Anthropol 1920; 3 : 429-66.

[4] Hrdlicka A. Further studies of tooth morphology. Am J Phys Anthropol 1921; 4: 141-76.

[5] Dahlberg AA. The dentition of the American Indian. In: Laughlin WS, Ed. Dental anthropology. Papers on the physical anthropology of the American Indian. Fourth Viking Fund summer seminar. The Viking Fund, Inc., New York, 1951; pp. 138-76.

[6] Lasker GW. Observations on the teeth of Chinese born and reared in China and America. Am J Phys Anthropol 1945; 3: 129-150.

[7] Lasker GW. Genetic analysis of racial traits of the teeth. Cold Spring Harbor Symposia on Quantitative Biology, XV 1951; pp. 191-203.

[8] Tratman EK. A comparison of the teeth of people: Indo-European racial stock with the Mongoloid. Dent Rec 1950; 70: 63-88.

[9] Moorrees CFA. Genetic considerations in dental anthropology. Genetetic and dental health. New York: Mc Graw Hill 1962; pp. 101-112.

[10] Carbonell VM. Variations in the frequency of shovel-shaped incisors in different populations. In: Brothwell DR, Ed. Dental Anthropology. Symposia of the Society for the study of human biology. New York: Pergamon Press 1963; Vol. 5.

[11] Palomino H, Chakraborty R, Rothhammer F. Dental morphology and population diversity. Hum Biol 1977; 49: 61-70.

[12] Greene DL. Genetics, dentition, and taxomony. Univ Wyom Pub 1967; 33: 93-168.

[13] Gregory WK. The origin and evolution of the human dentition. Baltimore: Williams \& Wilkins 1922.

[14] Suzuki M, Sakai T. Shovel shaped incisors among the living Polynesians. Am J Phy Anthropol 1964; 22: 65-72.
[15] Turner II CG. The dentition of the Arctic Peoples. PhD. Dissertation. Univ Wisconsin, Madison, 1967.

[16] Hellman M. Racial characters in human dentition. Proc Am Philos Soc 1929; 67: 157-74.

[17] Dahlberg AA. Analysis of the American Indian dentition. In: Brothwell DR Ed. Dental Anthropology. London: Pergamon 1963; pp. 149-77.

[18] Mayhall JT, Saunders SR, Belier PL. The dental morphology of North American Whites: a reappraisal. In Kurtn ed. Teeth: Form, function and evolution. Columbia Univ Press: New York, 1982; pp. 245-258.

[19] Scott GR. Dental morphology. A genetic study of American White families and variation in living Southwest Indians. PhD. Dissertation. Arizona State Univ 1973; pp. 1-244.

[20] Dahlberg AA. The changing dentition of man. J Am Dent Assoc 1945; 32: 676-90.

[21] Sofaer JA, MacLean CJ, Bailit HL. Heredity and morphological variation in early and late developing human teeth of the same morphological class. Arch Oral Biol 1972; 17: 811-6.

[22] Dahlberg AA. Relationship of tooth size to cusp number and groove conformation of occlusal surface. Patterns of lower molar teeth. J Dent Res 1961; 40(1): 34-8.

[23] Garn SM, Lewis AB, Kerewsky RS. Sexual dimorphism in the buccolingual tooth diameter. J Dent Res 1966; 45: 819.

[24] Ling JYK. A morphometric study of the dentition of 12-year-old Chinese children in Hong Kong: The University of Hong Kong, 1992.

[25] King NM, Ling BV. The dental caries status and dental treatment patterns of 12-year-old children in Hong Kong. J Dent Res 1986 65: $1371-4$

[26] Scott GR, Turner II CG. Trait descriptions. In: Scott GR, Turner II CG, Eds. The anthropology of modern human teeth. Cambridge: Cambridge Univ Press 1997; pp. 44-45.

[27] Scott GR, Turner II CG. Geographic variation in tooth crown and root morphology. In: Scott GR, Turner II CG, Eds. The anthropology of modern human teeth. Cambridge Univ Press: Cambridge, 1997; p. 204.

[28] Scott GR, Turner II CG. Geographic variation in tooth crown and root morphology. In: Scott GR, Turner II CG, Eds. The anthropology of modern human teeth. Cambridge Univ Press, Cambridge, 1997; p. 211

[29] Scott GR, Turner II CG. Geographic variation in tooth crown and root morphology. In: Scott GR, Turner II CG, Eds. The anthropology of modern human teeth. Cambridge Univ Press: Cambridge 1997; pp. 216-17.

[30] Scott GR, Turner II CG. Geographic variation in tooth crown and root morphology. In Scott and Turner ed. The anthropology of modern human teeth. Cambridge Univ Press, Cambridge, 1997; 217.

[31] Carlsen O, The Permanent Lower Molars. In Dental Morphology. Munksgaard, Copenhagen, 1987; 144-146.

(C) Ling and Wong; Licensee Bentham Open.

This is an open access article licensed under the terms of the Creative Commons Attribution Non-Commercial License (http://creativecommons.org/licenses/by-nc/3.0/) which permits unrestricted, non-commercial use, distribution and reproduction in any medium, provided the work is properly cited. 